\title{
Analysis of Factors Limiting the Blast Furnace Productivity*
}

\author{
By Kiyoshi Segawa** and Hideki Ishikawa**
}

\begin{abstract}
Synopsis
The blast furnace productivity has been investigated to obtain the clear and comprehensive understandings of the effects of the various phenomena in the furnace or of the operation conditions.

In the current investigation, an analysis standing on the chemical engineering viewpoint has been made on the phenomena, such as the hanging due to flooding, the blowing-through of the gas, the heat transfer between gas and solids, and the reduction of iron ore which are considered as the major limiting factors for the productivity. Equations representing the conditions for stable furnace operation have been derived from the parameters determined for these phenomena and the values of constants indicating the critical conditions which are estimated from the data of recent practical operation.

By the application of the relations obtained, some considerations have also been given on the special operations such as the oxygen enriched, the high top pressure, and the low-shaft furnace operations.

The method and result of present analysis seem to be useful for the furnace design and the selection of operation conditions.
\end{abstract}

\section{Introduction}

On the productivity of a blast furnace, numerous informations have been accumulated through the experiences of the furnace operation for many years. However, the effects of various operation conditions on the productivity have not been elucidated yet because of the complexity of the phenomena occurring in the furnace. Due to the reason mentioned above, more detailed, theoretical, and quantitative studies are required to make further progress in the blast furnace operation.

Methods and knowledge which are familiar in the field of chemical engineering may be advantageous for such analyses. Actually, various chemical and physical phenomena in the blast furnace have been studied by many investigators from the chemical engineering viewpoint. ${ }^{1,2), 11)}$ On the basis of these studies, a new method of analysis has been developed to obtain the synthetic knowledge on the relation between the operation conditions and the blast furnace productivity. In the present study, the following four phenomena are chosen as the major factors restricting the productivity.

(1) Hanging due to flooding

(2) Blowing-through of the gas

(3) Heat transfer between gas and solids

(4) Reduction of iron ore

In order to obtain the clear and synthetic understandings of the problem how these phenomena restrict the productivity, an analysis has been made on the effects of various operation conditions for these phenomena such as the grain size of the charge, the rate of air blast, or the dimension of the furnace. Several equations representing the conditions of stable blast furnace operation have been derived by using the limiting constants estimated from the recent practical operation data.

In addition, some considerations have also been made on the special blast furnace operations such as the oxygen enriched, the high top pressure, or the low shaft furnace operations, by applying the relations obtained. It may be expected that the results and methods of analysis presented in this paper will give some contributions for obtaining the valuable informations on the production increase of the blast furnace.

\section{Analysis of Various Phenomena in Furnace}

\section{Hanging due to Flooding}

Among the hangings taking place in the blast furnace by various causes, only the hanging due to the flooding in the molten zone has been studied in the present work.

On this kind of hangings, Elliott and Wagstaff stated that the critical condition can be defined by the use of the following two parameters :

$$
\begin{aligned}
\text { Hanging factor } & =\left(V_{G}^{2} S_{o} / g \cdot \varepsilon^{3}\right)\left(\rho_{G} / \rho_{L}\right) \mu_{L}^{0.2} \\
\text { Fluid ratio } & =(L / G)\left(\rho_{G} / \rho_{L}\right)^{0.5}
\end{aligned}
$$

$$
\begin{aligned}
& \text { where, } V_{G}: \text { superficial gas velocity, }(\mathrm{m} / \mathrm{sec}) \\
& \rho_{G}, \rho_{L}: \text { densities of gas and liquid, }\left(\mathrm{t} / \mathrm{m}^{3}\right) \\
& \mu_{L}: \text { viscosity of liquid, (centi-poise) } \\
& G, L: \text { gas and liquid mass velocities, }\left(\mathrm{t} / \mathrm{m}^{2} \cdot \mathrm{sec}\right) \\
& S_{o}=6(1-\varepsilon) / \phi d: \text { specific surface of solid particles, }\left(\mathrm{m}^{2} / \mathrm{m}^{3}\right) \\
& \varepsilon: \quad \text { porosity fraction of the bed } \\
& \phi: \text { sphericity factor of solid particles } \\
& g: \text { gravity constant, } \quad\left(=9.8 \mathrm{~m} / \mathrm{sec}^{2}\right) .
\end{aligned}
$$

From the data of Sherwood, ${ }^{3)}$ from the results obtained in their own experiment, and from the practical operation data, they found that there is a correlation of hanging as shown in Fig. 1. Based on this figure, it was considered that the critical condition of hanging might be expressed by the following equation.

$$
\text { (Hanging factor) }{ }^{2} \text {. (Fluid ratio) }<10^{-3}
$$

This relation is shown by the straight line in Fig. 1.

If the relation between the gas velocity $V_{G}$ and the grain size of coke $d_{c}$ is only taken into account, the above equation can be rewritten as follows :

$$
K_{1}\left(V_{G}^{2} / d_{c}\right)^{2}<10^{-3}
$$

where,

$$
K_{1}=\left(\frac{6(1-\varepsilon)}{\varepsilon^{8} \dot{\phi} g}\right)^{2}(L / G)\left(\rho_{G} / \rho_{L}\right)^{2.5} \mu_{L}^{0.4}
$$

In Eqs. (2) and (3), the grain size of solids is repre- 


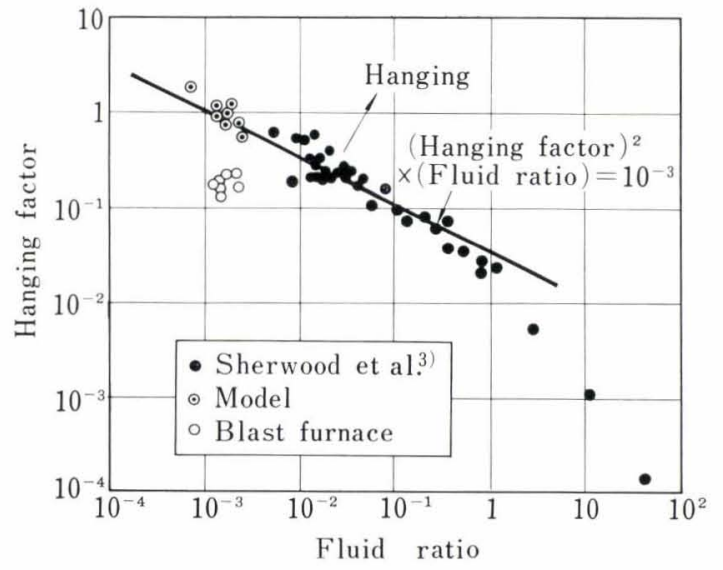

Fig. 1. Correlation of hanging due to flooding ${ }^{2}$

sented by the coke size $d_{c}$ because it is considered that the most of solids existing in the molten zone are coke.

If the temperature and pressure of the gas are approximately constant, the following relation may be realized; $V_{G} \propto W / D^{2}$. Substituting this relation into Eq. (3), the condition for the operation without hanging is expressed as follows :

$$
W /\left(D^{2} \cdot \sqrt{\left.d_{c}\right)}<C_{1}\right.
$$

where, $\quad C_{1}$ : constant (upper limit of $W / D^{2} \cdot \sqrt{d_{c}}$ for stable operation).

In the above equation, the left term $W /\left(D^{2} \cdot \sqrt{d_{c}}\right)$ is considered as a parameter related to the hanging. The relation between the parameter mentioned above and the hanging was examined with the data of recent operation of four Kukioka blast furnaces and the result shown in Fig. 2 was obtained.

Although the data obtained show a considerable scattering, it is clearly observed that there is a correlation between the monthly means of $W /\left(D^{2} \cdot \sqrt{d_{c}}\right)$ and the number of hanging per month. From this result, it is evident that hanging takes place frequently when the parameter is larger than a certain specified value.

The critical value $C_{1}$ of Eq. (4) is difficult to estimate by calculation because the accurate values are hardly obtained for many variables contained in $C_{1}$. It was therefore estimated from the practical operation data

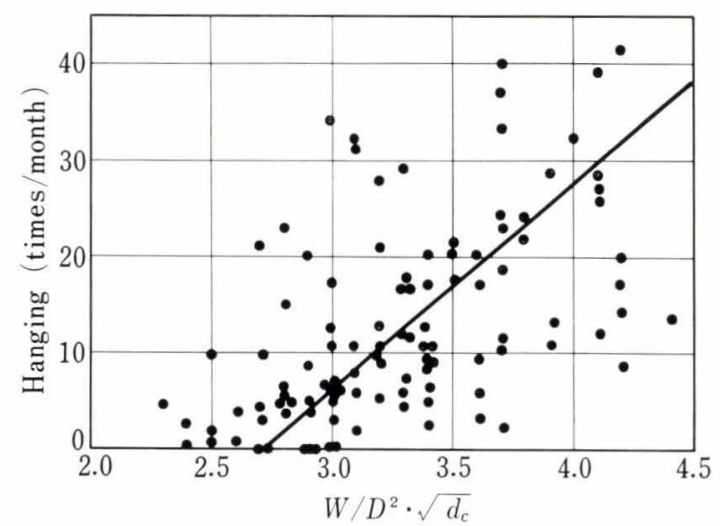

Fig. 2. Relation between $W / D^{2} \cdot \sqrt{\overline{d_{c}}}$ and hanging (Kukioka blast furnaces, Jan., 1961 to Jan., 1965) based on the assumption that the present blast furnaces are operated under the conditions near the production limit. That is, the value of $C_{1}$ was determined so as to contain ninety per cent of the monthly averaged values of $W /\left(D^{2} \cdot \sqrt{d_{c}}\right)$ obtained from the data of the last four years.

In the current work, the range covering ninety per cent of the data is only taken as a criterion for the determination of $C_{1}$. It should, however, be noticed that it is questionable whether this criterion is adequate or not. Further studies are therefore necessary to find a more accurate critical value. Substituting this value into Eq. (4), the following relation for the operation without hanging is obtained.

$$
\begin{aligned}
& W /\left(D^{2} \cdot \sqrt{d_{c}}\right)<4.2 \\
& d_{c}>0.057\left(W / D^{2}\right)^{2}
\end{aligned}
$$

or

In the case of oxygen enriched blast, the rate of air blast $W$ is corrected by the following equation.

$$
W=W_{o}\left\{1+\frac{2}{100}\left(\Delta \mathrm{O}_{2}\right)\right\}
$$

where, $W:$ corrected rate of air blast, $\left(\mathrm{Nm}^{3} / \mathrm{min}\right)$

$W_{o}$ : observed rate of air blast, $\left(\mathrm{Nm}^{3} / \mathrm{min}\right)$

$\Delta \mathrm{O}_{2}$ : concentration of enriched oxygen, (\%).

The same correction is also adopted for the rate of air blast in the following sections.

\section{Pressure Drop and Blowing-Through of Gas Flow}

There are several reports ${ }^{1,4), 5}$ ) concerning the analysis of pressure drop in a blast furnace shaft. However, only the result reported by Philbrook ${ }^{1)}$ is cited here.

The pressure drop of gas flow through a bed of solid particles is given by the following equation.

$$
\Delta P=f\left(\frac{G^{2}}{\rho_{G} \cdot g_{c}}\right)\left(\begin{array}{c}
H \cdot S_{o} \\
\varepsilon^{3}
\end{array}\right)
$$

where, $\Delta P:$ pressure drop across the bed, $\left(\mathrm{kg} / \mathrm{m}^{2}\right)$

$G$ : superficial mass velocity of gas, $\left(\mathrm{kg} / \mathrm{m}^{2} \cdot \mathrm{sec}\right)$

$\rho_{G}:$ density of gas, $\left(\mathrm{kg} / \mathrm{m}^{2}\right)$

$H$ : height of the bed, (m)

$f:$ friction factor

$g_{c}$ : dimensional constant, $\quad\left(9.8 \mathrm{~kg} \mathrm{~m} / \mathrm{sec}^{2} \cdot \mathrm{kg}\right)$.

In the above equation, friction factor $f$ is a function of Reynolds' number $\mathcal{N}_{\mathrm{Re}}\left(=G / \mu_{G} S_{o}\right)$ and the relation between $f$ and $\mathcal{N}_{\operatorname{Re}}$ is approximately given by the following equation under the condition in the blast furnace shaft :

$$
f=1.25 \mathcal{N}_{\mathrm{Re}}^{-0.3}
$$

Substituting Eq. (7) for Eq. (6), the following equation is obtained.

$$
\Delta P=\kappa_{2} H G^{1.7} / d^{1.3}
$$

where,

$$
\begin{aligned}
& K_{2}=1.25\left\{\frac{6(1-\varepsilon)}{\phi}\right\}^{1.3} \frac{\mu_{G}^{0.3}}{\varepsilon^{3}} \frac{1}{\rho_{G} \cdot g_{c}} \\
& d: \text { grain size of solid particles, }(\mathrm{mm}) .
\end{aligned}
$$


The same treatment reported by Philbrook $^{2)}$ was used for the blowing-through of gas flow. It is considered that the local fluidization takes place and it causes the blowing-through when the pressure drop across the bed is enough to support the weight of solids per unit area.

$$
\Delta P>\alpha H(1-\varepsilon) \rho_{S}
$$

Usually the value of $H(1-\varepsilon) \rho_{S}$ is far greater than the pressure drop. It appears, however, that the blowing-through becomes significant when the ratio $\triangle P / H$ $(1-\varepsilon) \rho_{S}$ exceeds some critical value $\alpha$. Assuming that $\mu_{G}, \rho_{G}, \rho_{S}$, and $\varepsilon$ are constant, the follownig relation is obtained from Eqs. (8) and (9).

$$
G^{1.7} / d^{1.3}<C_{2}^{\prime}
$$

where, $C_{2}^{\prime}$ : constant.

Since the mass velocity of gas $G$ is proportional to $W / D^{2}$, the above relation is rewritten as follows:

$$
\left(W / D^{2}\right)^{1.3} / d<C_{2}
$$

where, $C_{2}$ : constant.

This relation shows the condition necessary for the operation without blowing-through. Though the surface-average particle size of ore and coke should be used for $d$ in the above equation, two equations obtained by substituting $d_{c}$ and $d_{o}$ for $d$ of Eq. (10) are used for the sake of simplicity in the following discussion. The left term of Eq. $(10),\left(W / D^{2}\right)^{1.3} / d$, is considered as a parameter concerning the blowing-through. From the examination of the recent operation data of the Kukioka and Tobata blast furnaces, it was found that there was a correlation between the value of this parameter and the amount of flue-dust. This result may evidently indicate the meaning of Eq. (10) that the value of $\left(W / D^{2}\right)^{1.3} / d$ must be smaller than a certain critical value for the stable operation without the production of a large amount of flue-dust or the blowing-through.

The critical value of $C_{2}$ in Eq. (10) was determined from the recent practical operation data, since it was difficult to estimate by calculation from the same reason as mentioned previously. Monthly averaged values of $X_{c}$ and $X_{o}$ defined by the following equations were calculated for each of the Kukioka and Tobata blast furnaces.

$$
X_{c}=\left(W / D^{2}\right)^{1.3} / d_{c}
$$

$$
X_{o}=\left(W / D^{2}\right)^{1.3} / d_{o}
$$

where, $d_{c}, d_{o}$ : grain sizes of coke and ore, respectively $(\mathrm{mm})$.

In the same way as described in the preceeding section, the limiting values of $X_{c}$ and $X_{o}$ are determined so as to contain ninety per cent of the monthly averaged values, and are listed in Table 1 . Substituting these values for Eq. (10), the following equations are obtained.

$$
\begin{aligned}
& \left(W / D^{2}\right)^{1.3} / d_{c}<1.7 \\
& \left(W / D^{2}\right)^{1.3} / d_{o}<5.0
\end{aligned}
$$

These equations are also rewritten as follows :

$$
\begin{aligned}
& d_{c}>0.6\left(W / D^{2}\right)^{1.3} \\
& d_{o}>0.2\left(W / D^{2}\right)^{1.3}
\end{aligned}
$$

\section{Heat Transfer between Gas and Solids}

For the stable operation of the blast furnace, it is necessary to give a suitable amount of heat for solids. Temperature of the gas and solids in any part of the shaft can be calculated from the following equations by assuming that the amount of heat lost from the wall and consumed by chemical reactions is negligible.

The amount of heat transfered from gas to solids at a thin cross section is,

$$
d Q=-C_{S} \cdot V_{S} \cdot d T_{S}=k\left(T_{G}-T_{S}\right) d x
$$

where, $x$ : height of the section from the bottom of furnace shaft, (m)

$V_{S}$ : descending velocity of solids, $(\mathrm{m} / \mathrm{sec})$

$C_{G}, C_{S}:$ specific heats of gas and solids respectively, $\left(\mathrm{kcal} / \mathrm{m}^{3}{ }^{\circ} \mathrm{C}\right.$ )

$T_{G}, T_{S}:$ temperatures of gas and solids at $x$ respectively, $\left({ }^{\circ} \mathrm{C}\right)$

$k$ : heat transfer coefficient between gas and solids, $\left(\mathrm{kcal} / \mathrm{m}^{3} \sec { }^{\circ} \mathrm{C}\right)$.

In the above equation, $T_{G}$ can be substituted by $T_{S}$ using the following relation of heat balance in the shaft.

\begin{tabular}{|c|c|c|c|c|c|c|}
\hline Furnace & $\begin{array}{c}\text { Kukioka } \\
\text { l B.F. }\end{array}$ & $\begin{array}{c}\text { Kukioka } \\
2 \text { B.F. }\end{array}$ & $\begin{array}{c}\text { Kukioka } \\
3 \text { B.F. }\end{array}$ & $\begin{array}{c}\text { Kukioka } \\
4 \text { B.F. }\end{array}$ & $\begin{array}{l}\text { Tobata } \\
1 \text { B.F. }\end{array}$ & $\begin{array}{l}\text { Tobata } \\
2 \text { B.F. }\end{array}$ \\
\hline Number of data & 33 & 33 & 11 & 33 & 33 & 33 \\
\hline $90 \%$ range of $X_{c}$ & $1.0 \pm 0.3$ & $1.0 \pm 0.3$ & $1.2 \pm 0.3$ & $1.4 \pm 0.3$ & $1.4 \pm 0.3$ & $1.4 \pm 0.3$ \\
\hline $90 \%$ range of $X_{0}$ & $3.1 \pm 0.6$ & $3.1 \pm 0.6$ & $3.5 \pm 0.6$ & $3.5 \pm 0.8$ & $3.5 \pm 1.2$ & $3.5 \pm 1.2$ \\
\hline $90 \%$ range of $10\left(\mathrm{H}_{c}\right.$ & $1.54 \pm 0.20$ & $1.69 \pm 0.18$ & $1.56 \pm 0.12$ & $1.57 \pm 0.15$ & $1.44 \pm 0.12$ & $1.46 \pm 0.12$ \\
\hline $90 \%$ range of $10(\mathrm{H})_{0}$ & $1.09 \pm 0.20$ & $1.23 \pm 0.16$ & $1.13 \pm 0.08$ & $1.15 \pm 0.12$ & $1.12 \pm 0.08$ & $1.14 \pm 0.10$ \\
\hline $90 \%$ range of $Y$ & $74 \pm 9$ & $74 \pm 8$ & $74 \pm 6$ & $77 \pm 8$ & $74 \pm 8$ & $70 \pm 8$ \\
\hline
\end{tabular}

$$
C_{G} \cdot V_{G}\left(T_{G}-T_{G}^{0}\right)=C_{S} \cdot V_{S}\left(T_{S}-T_{S}^{0}\right)
$$

where, $T_{G}^{0}, T_{S}^{0}$ : temperatures of gas and solids at $x=0$, respectively.

The following differential equation is thus obtained,

$$
-d T_{S} / d x=k\left(A+B T_{S}\right) / C_{S} \cdot V_{S}
$$

where, $A=T_{G}^{0}-\frac{C_{S} \cdot V_{S}}{C_{G} \cdot V_{G}} T_{S}^{0}, \quad B=\left(\frac{C_{S} \cdot V_{S}}{C_{G} \cdot V_{G}}\right)-1$,

Table 1. Results of operation data analysis (Jan., 1961 to Jan., 1965) 
the boundary condition is $T_{S}=0$ at $x=H$.

Solution of Eq. (15) is given by

$$
1+\frac{B T_{S}}{A}=\exp \frac{B k}{C_{S} \cdot V_{S}}(H-x)
$$

Assuming that the right term of Eq. (16) can be obtained by linear approximation and that the left term can be expressed by the following approximation :

$$
\begin{aligned}
\frac{B}{A} T_{S} & =\frac{B T_{S}}{T_{G}^{0}-\frac{C_{S} \cdot V_{S}}{C_{G} \cdot V_{G}}\left(T_{S}^{0}\right)} \\
& =\frac{B T_{S}}{T_{G}^{0}}\left[1+\left(\frac{C_{S} \cdot V_{S}}{C_{G} \cdot V_{G}}\right)\left(\frac{T_{S}^{0}}{T_{G}^{0}}\right)\right]
\end{aligned}
$$

Eq. (16) becomes as follows :

$$
\left(\frac{T_{S}}{T_{G}^{0}}\right)\left[1+\left(\frac{T_{S}^{0}}{T_{G}^{0}}\right)\left(\frac{C_{S} \cdot V_{S}}{C_{G} \cdot V_{G}}\right)\right]=\frac{K}{C_{S} \cdot V_{S}}(H-x)
$$

On the other hand, the heat transfer coefficient $k$ is approximately proportional to $(\mathrm{Re})^{0.7}$ and to $d^{-1}$.

$$
k \propto(\mathrm{Re})^{0.7} / d \propto\left(W / D^{2}\right)^{0.7} \cdot d^{-0.3}
$$

For convenience sake, the following assumptions are made considering that the coke ratio is approximately proportional to $\left(V_{G} / V_{S}\right)$.

$$
\begin{gathered}
\left(T_{S}^{0} / T_{G}^{0}\right)\left(\frac{C_{S} \cdot V_{S}}{C_{G} \cdot V_{G}}\right) \fallingdotseq 0.5(1 / \eta) \\
V_{S} \propto V_{G} / \eta \propto\left(W / D^{2}\right) / \eta
\end{gathered}
$$

Substituting these relations for Eq. (17), the following equation is obtained,

$$
\left(\mathcal{T}_{S} / \mathcal{T}_{G}^{0}\right)(1+0.5 / \eta) \propto\left(W / D^{2}\right)^{-0.3} \cdot d^{-0.3}(H-x)\left(\eta / C_{S}\right)
$$

The following approximation may be realized in the normal blast furnace operation.

$$
1 / \eta(1+0.5 / \eta) \fallingdotseq 8(1-\eta) \quad(0.4<\eta<0.7)
$$

Substituting this relation into Eq. $(17)^{\prime}$, Eq. (18) is obtained.

$$
\left(\frac{1}{T_{S}}\right)\left(\frac{H-x}{H}\right)=K_{3}\left(W / D^{2}\right)^{0.3} \cdot d^{0.3}(1-\eta) / H \ldots
$$

For the stable operation of blast furnace, a suitable amount of heat must be transfered from gas to solids, because the excess supply of heat causes irrational high location of molten zone, and the short supply of heat causes irrational low location. In order to maintain the smelting zone at an appropriate position, the left term of Eq. (18) is required to be in a certain specified range. The relation necessary for the suitable heat transfer is therefore expressed as follows:

$$
C_{3}^{\prime}<\left(W / D^{2}\right)^{0.3} \cdot d^{0.3}(1-\eta) / H<C_{3}
$$

where, $C_{3}, C_{3}^{\prime}$ : constants (critical values for the suitable heat transfer).

By the same reason as mentioned above, the critical values $C_{3}$ and $C_{3}^{\prime}$ were estimated from the data of recent practical operation. (11) $)_{c}$ and $\mathbb{( I I}_{o}$ defined by the following equations are calculated from the monthly averaged data in order to obtain the critical values $C_{3}$ and $C_{3}^{\prime}$.

$$
\begin{aligned}
& \text { (ii) }_{c}=\left(W / D^{2}\right)^{0.3} \cdot d_{c}^{0.3}(1-\eta) / H \\
& \text { (ii) }_{o}=\left(W / D^{2}\right)^{0.3} \cdot d_{o}^{0.3}(1-\eta) / H
\end{aligned}
$$

The ninety per cent ranges of $\mathbb{H}_{c}$ and $\mathbb{H}_{0}$ for each of the Kukioka and Tobata blast furnaces are shown in Table 1.

The critical values of $C_{3}$ and $C_{3}^{\prime}$ for $\mathbb{H}_{c}$ and $\mathbb{H}_{o}$ were determined so as to contain ninety per cent of the monthly averaged values.

Substituting these values for Eq. (19), the following equations are obtained.

$$
\begin{aligned}
& 0.142<\left(W / D^{2}\right)^{0.3} \cdot d_{c}^{0,3}(1-\eta) / H<0.175 \\
& 0.100<\left(W / D^{2}\right)^{0.3} \cdot d_{o}^{0.3}(1-\eta) / H<0.127
\end{aligned}
$$

\section{Reduction of Iron Ores in a Furnace}

Reduction of iron ores has been widely investigated, and several quantitative rate equations have been determined for lump ores ${ }^{6)}$ or for iron ore pellets.

In the present analysis, however, it is desirable to apply the equation having a simple form.

The relation among the rate of reduction $y$, reduction time $t$, and the time for complete reduction $t_{B}$ is shown by the following equation.

$$
t / t_{B}=1-(1-y)^{1 / 3}
$$

The relation between $t_{B}$ and the grain size of ore $d_{o}$ was examined by the results obtained from the reduction experiments of various kinds of ore. Fig. 3 (a) shows the result of a reduction experiment carried out in a hydrogen atmosphere at $800^{\circ} \mathrm{C}$, and Fig. 3 (b) shows the result obtained in a mixed gas atmosphere $\left(\mathrm{CO} 30 \%+\mathrm{N}_{2} 70 \%\right.$ ) at $900^{\circ} \mathrm{C} .{ }^{7)}$ Grain size of ores charged in the blast furnace ranges from 5 to $40 \mathrm{~mm}$, and the following empirical rate equation may be used in this range of grain size distribution from the results shown in Fig. 3.

$$
\frac{t}{1-\sqrt[3]{1-y}}=R d_{o}+t_{o}
$$

Where $R$ and $t_{o}$ are constants, whose values are shown in Table 2 in the cases of $\mathrm{H}_{2}$ and $\mathrm{CO}$ reductions.

To make sufficient reduction in a shaft, it is necessary to maintain the traveling time of ores longer than the time $t$ required for the reduction.

$$
\theta>t=a\left(t_{o}+R d_{o}\right)
$$

Table 2. Constants in rate equation

\begin{tabular}{c|c|c}
\hline Reduction condition & $t_{o}$ (min) & $R$ (min/mm) \\
\hline With $\mathrm{H}_{2}$ at $800^{\circ} \mathrm{C}$ & 100 & $\begin{array}{l}5 \text { (Magnetite ores) } \\
3 \text { (Hematite ores) }\end{array}$ \\
\hline $\begin{array}{c}\text { With a mixed gas } \\
\text { at } 900^{\circ} \mathrm{C}\end{array}$ & 200 & 10 to 30 \\
\hline
\end{tabular}




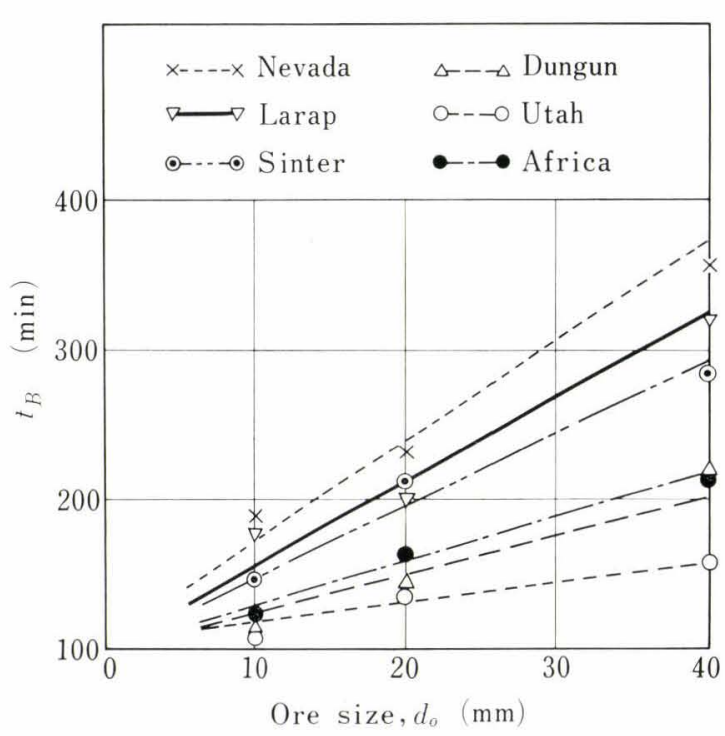

(a)

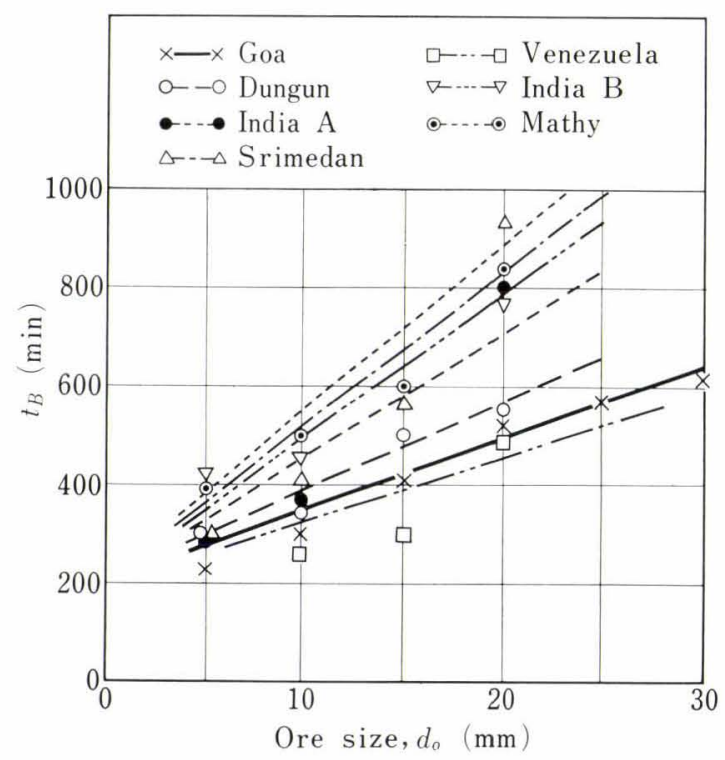

(b)

Fig. 3. Relation between ore size $d_{o}$ and time for complete reduction $t_{B}\left(=t /\left\{1-(1-\mathrm{y})^{1 / 3}\right\}\right)$

(a) With $\mathrm{H}_{2}$ at $800^{\circ} \mathrm{C}$

(b) With a mixed gas $\left(\mathrm{CO} 30 \%-\mathrm{N}_{2} 70 \%\right)$ at $900^{\circ} \mathrm{C}^{7}$

In a practical furnace, $t$ is determined not only by $d_{o}$ but also the degree of indirect reduction and the composition of gas. Although the coefficient ' $a$ ' in the above equation is given as a function of these two factors, it is assumed to be a constant in the following discussion, as a matter of convenience.

The average traveling time $\theta$ of the charged solids is given by the following equation.

Traveling time

$$
\begin{aligned}
& \theta= \frac{(\text { Inner volume of the furnace } V)}{(\text { Volumetric charging rate) }} \\
&= \frac{V(1-\varepsilon)}{O / \rho_{O}+C / \rho_{O}}=(V / O)(O / C)[(1-\varepsilon) /\{(O / C) . \\
&\left.\left.1 / \rho_{O}+1 / \rho_{O}\right\}\right]
\end{aligned}
$$

where, $O, C$ : charging rates of ore and coke respectively, $(\mathrm{t} / \mathrm{min})$

$\rho_{O}, \rho_{C}:$ specific gravities of ore and coke respectively, $\left(\mathrm{t} / \mathrm{m}^{3}\right)$

$O / C:$ ore/coke ratio, $(\mathrm{t} / \mathrm{t})$.

When the composition of the charge is kept constant, the charging rate of ore is approximately proportional to the production rate, which is closely proportional to the rate of air blast in general. Assuming that the term in the bracket is kept constant, the traveling time of ores is expressed as follows :

$$
\theta=K_{4} H(O / C) /\left(W / D^{2}\right)
$$

By substituting Eq. (22) for Eq. (21), the condition necessary for the sufficient reduction is written as follows :

$$
\left(W / D^{2}\right) \frac{t_{o}+R d_{o}}{H(O / C)}<C_{4}
$$

where, $C_{4}:$ constant.

Left term of the above equation is considered to be a parameter representing the ratio, (time necessary for reduction)/(traveling time), and the greater this value is, the more incomplete the iron ore reduction is. As the result of examining the monthly averaged data of the recent practical operation, it was found that there was a correlation between the value of this parameter $\left(W / D^{2}\right)\left(t_{0}+R d_{0}\right) / H(O / C)$ and the rate of direct reduction calculated from the carbon balance, although the data were scattered rather widely. Validity of the present discussion may well be confirmed by the result described above.

The value of constant $C_{4}$ in Eq. (23) was estimated from the data of recent operation. Values of $Y$ defined by the following equation for each of the Kukioka and Tobata blast furnaces are listed in Table 1.

$$
Y=\left(W / D^{2}\right)\left(100+5 d_{o}\right) / H(O / C)
$$

From the same assumption as mentioned in the preceeding sections, the critical value of $C_{4}$ was estimated and the following equation showing the relation necessary for the sufficient reduction was obtained:

$$
\left(W / D^{2}\right)\left(100+5 d_{o}\right) / H(O / C)<84 .
$$

\section{Considerations on the Productivity}

Relations among the conditions for stable operation described in the preceeding chapter are summarized as follows :

(1) The condition required for the operation without hanging.

$$
d_{c}>0.057\left(W / D^{2}\right)^{2}
$$

(2) The rational relation for the operation without blowing-through.

$$
\begin{aligned}
& d_{c}>0.6\left(W / D^{2}\right)^{1.3} \\
& d_{o}>0.2\left(W / D^{2}\right)^{1.3}
\end{aligned}
$$

(3) The relation for suitable heat transfer in the furnace. 


$$
\begin{aligned}
& 0.175>\left(W / D^{2}\right)^{0.3} \cdot d_{c}^{0.3}(1-\eta) / H>0.142 \\
& 0.127>\left(W / D^{2}\right)^{0.3} \cdot d_{o}^{0.3}(1-\eta) / H>0.100 .
\end{aligned}
$$

(4) The relation for the sufficient reduction of iron ores.

$$
\left(W / D^{2}\right)\left(100+R d_{o}\right) / H(\text { Ore } / \text { Coke })<84
$$

From these equations, the range of stable operations can be determined on the $d_{c}$ or $d_{o}$ vs. $\left(W / D^{2}\right)$ diagram. Fig. 4 (a) and (b) show the results when $H$ is $25 \mathrm{~m}$, Ore/Coke is 2.7 and $\eta$ is 0.55 . In these figures, the hatched area indicates the range of suitable operations. In the regions $1,2,3$, and 4, the blast furnace operation may be unstable due to flooding, blowing-through, incomplete reduction, and shortage or excess of heat transfer respectively.

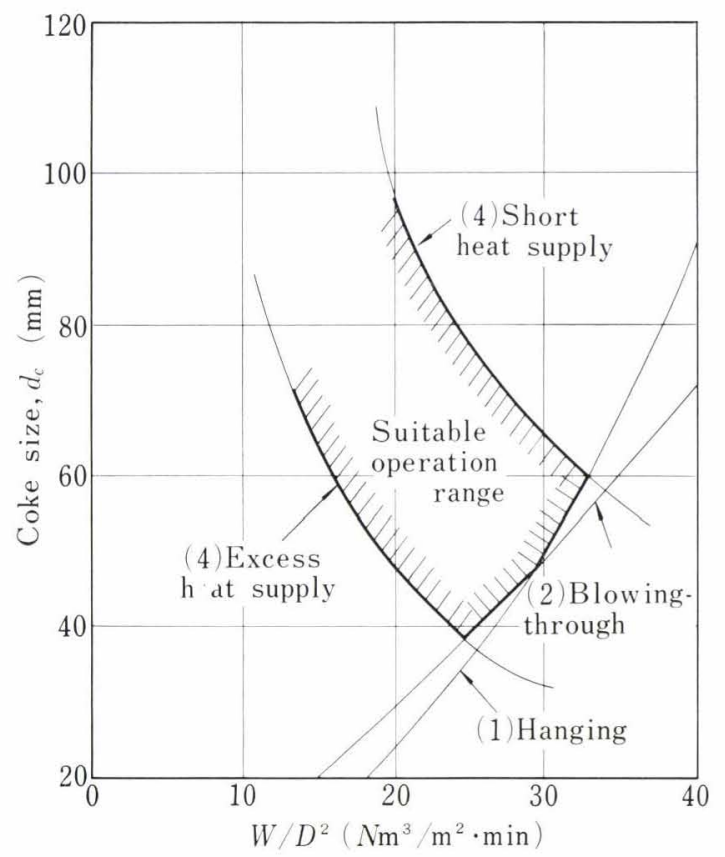

(a)

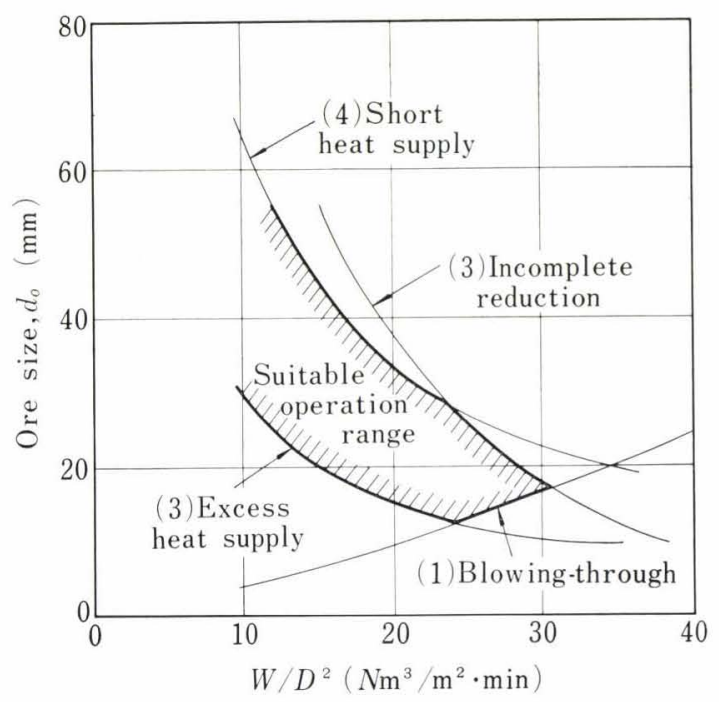

(b)

Fig. 4. Suitable operation range

(a) Coke size $d_{c}$ vs. $W / D^{2}$

(b) Ore size $d_{o}$ vs. $W / D^{2}$
Since the production rate of pig iron in a blast furnace is approximately proportional to the rate of air blast, it may be considered that the blast furnace producibility is given by the value of the abscissa in Fig. 4, i.e. $W / D^{2}$. Therefore, these graphical presentations give a clear information on the productivity limit stipulated by the various phenomena such as hanging, blowing-through, heat-transfer, and iron ore reduction. In addition, it is easily seen which phenomenon is the limiting factor in any part of Fig. 4 . One of the main purposes of the present analysis is to obtain the synthetic understandings on the effects of these phenomena on the blast furnace productivity, considering mutual relationships.

Numerical values of constant $C_{1}, C_{2}, C_{3}$, and $C_{4}$ in Eqs. (4), (10), (19), and (23) are not possible to estimate from calculations. These critical values were therefore determined from the recent operation data, assuming that the present blast furnaces are operated under the conditions near the production limit. However, it is questionable whether those obtained in the present analysis represent the true critical ones or not. It should therefore be mentioned here that the present work chiefly aims at introducing the method of analysis or the way of thinking, and that further studies should be carried out to find the more accurate quantitative relations.

\section{Considerations on the Special Operations}

The results obtained by the present analysis, Eqs. (25) to (28) and those shown in Fig. 4 are considered to be useful for the furnace design and the selection of operation conditions. For further utilization, these results were applied to the special operations of the blast furnace, such as the oxygen enriched operation or the high top pressure operation, and the low-shaft furnace operation, etc.

\section{Oxygen Enriched Operation}

Physical properties of the gas are changed scarcely by the oxygen enrichment of a few per cent. The conditions of flooding and blowing-through are characterized only by the aerodynamic properties of the system. Therefore the same equations as Eqs. (25) and (26) can also be used for this operation.

As for the reduction of iron ore due to the oxygen enriched blast, it is considered that the rate constant increases nearly in proportion to the $\mathrm{CO}$ content of the reduction gas and that the reduction time decreases nearly by $\left(\Delta \mathrm{O}_{2} / 0.21\right)$ per cent. On the other hand, the traveling time of ore decreases nearly by $\left(\Delta \mathrm{O}_{2} / 0.21\right)$ per cent as the result of the production increase. Position of the line in Fig. 4 which represents the reduction of iron ore scarcely changes because these two effects offset each other.

As for the equations of heat transfer, the specific heat of gas $C_{G}$ and the heat transfer coefficient $k$ are scarcely changed by oxygen enrichment. However, ores and cokes of smaller grain size must be charged in order to supply larger amount of heat per unit time since the descending velocity of solids, $V_{S}$, increases. Consequently, the line representing the heat transfer shifts 


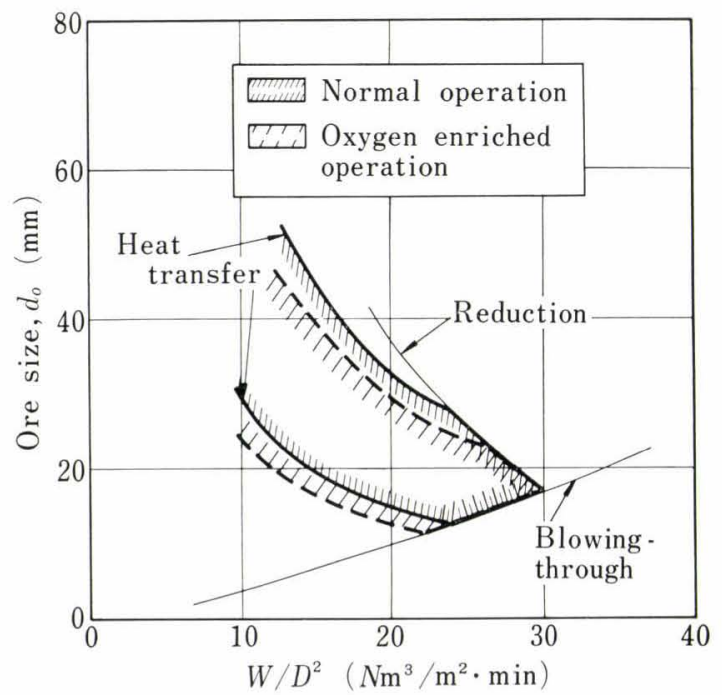

Fig. 5. Suitable range of oxygen enriched operation

down-ward as shown in Fig. 5. Nevertheless, as shown in Fig. 5, the restriction due to the heat transfer is less than that by the reduction in the region of large $W / D^{2}$.

From the considerations mentioned above, the following conclusions have been drawn.

(1) The range of optimum grain size does not largely change because of oxygen enrichment of the blast, but the restriction due to the heat transfer may be significant and the finer ore becomes desirable when the degree of oxygen enrichment is too high.

(2) In Fig. 5, the maximum allowed to $W / D^{2}$ does not change because of oxygen enrichment of the blast. However, the production increase of about $\left(\Delta \mathrm{O}_{2} / 0.21\right)$ per cent may be expected from the reason that the production rate is nearly proportional to the oxygen content in the air blast.

The production increase by the oxygen enrichment of one per cent is estimated to be about five per cent. As shown in Fig. 6, this estimation is ascertained by the data obtained in the practical oxygen enriched operations of the Higashida and Tsurumi ${ }^{8)}$ blast furnaces.

\section{High Top Pressure Operation}

By raising the inner pressure of the blast furnace,

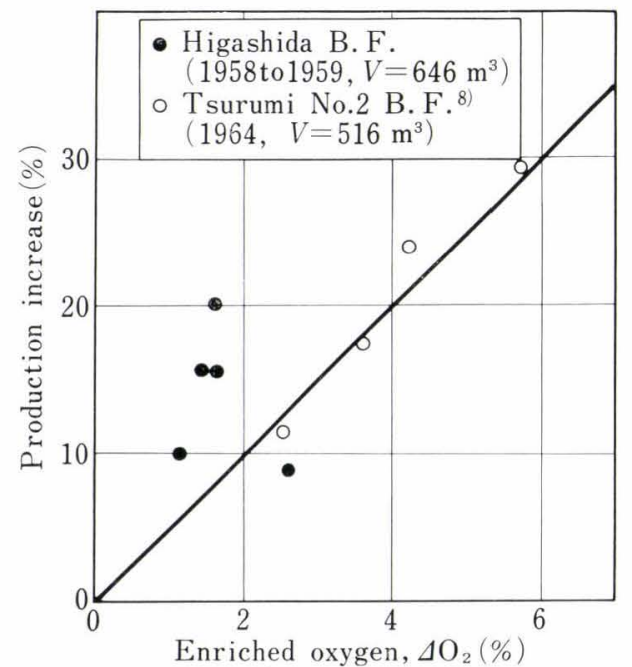

Fig. 6. Production increase by oxygen enrichment the gas density $\rho_{G}$ and the gas stream velocity $V_{G}$ change after following relations,

$$
V_{G} \propto p^{-1}, \quad \rho_{G} \propto p
$$

where, $p=P / P_{0}$

$P:$ average pressure in furnace for high pressure operation

$P_{0}:$ average pressure for normal operation.

(1) In the equation referring to the hanging, the relation between coke size $d_{c}$ and the gas velocity $V_{G}$ is expressed as follows:

$$
d_{c}>C \cdot V_{G}^{2}
$$

Constant $C$ in the above equation is proportional to $p^{1.25}$, because $K_{1}$ in Eq. (3) is proportional to $p^{2.5}$. The equation is $d_{c}^{\circ}>C_{0} \cdot V_{G}^{\circ}$ for normal operation and $d_{c}>C V_{G}=\left(p^{1.25} \cdot C_{0}\right)\left(p^{-2.0} V_{G}^{\circ}\right)$ for high pressure operation. Thus, $d_{c}=p^{-0.75} d_{c}^{\circ}$.

From the above relations, the suitable grain size of coke decreases in inverse proportion to $p^{0.75}$, if the inner pressure is $p$-times larger than the initial pressure.

(2) In the same way, it is known from Eq. (10) referring to the blowing-through, that the suitable grain size of solids is decreased in inverse proportion to $p^{0.6}$, when the inner pressure is $p$-times larger than the initial ones.

For normal operation: $\quad d^{0}>C_{0}^{\prime} G_{o}^{1.3}$

For high pressure operation: $\quad d>C^{\prime} G^{1.3}$ $=\left(p^{-0.6} \cdot C_{o}^{\prime}\right) G_{0}^{1.3}$

Thus, $d=d^{\circ} p^{-0.6}$

(3) In the equations of heat transfer, the term of gas velocity $V_{G}$ is always given in the form of $V_{G} \cdot C_{G}$ or $V_{G} \cdot \rho_{G}$, and these values are constant regardless of the inner pressure. It is therefore theoretically concluded that the pressure increase has no influence on the heat transfer.

(4) At present, insufficient amount of experimental data is only available for the reduction of iron ore with a high pressure gas.

It is presumed that the rate constant of iron ore reduction is nearly proportional to the inner pressure, since the partial pressure of $\mathrm{CO}$ is proportional to it. On the other hand, the decrease in the gas velocity may have a decreasing effect for the reduction velocity. If the rate constant is proportional to $p^{m}$, the suitable grain size of ores is approximately proportional to $p^{-m}$. The value of $m$ is considered to be between 0 and 1 from the reasons described above.

From the above relations, in the cases of $P=P_{0}$ (normal operation), $P=1.5 P_{0}$, and $P=2.0 P_{o}$, the suitable operation ranges change as shown in Fig. 7, where the rate of reduction is assumed to be proportional to $p^{0.5}$.

From this figure, the following conclusions are drawn.

(1) Optimum size ranges of coke and ore change scarcely.

(2) The productivity is expected to increase by 10 to $20 \%$ if the inner pressure is 1.5 times as much as the initial one.

(3) In the high pressure operation, the hanging is 
considered to be a more significant limiting factor than the blowing-through.

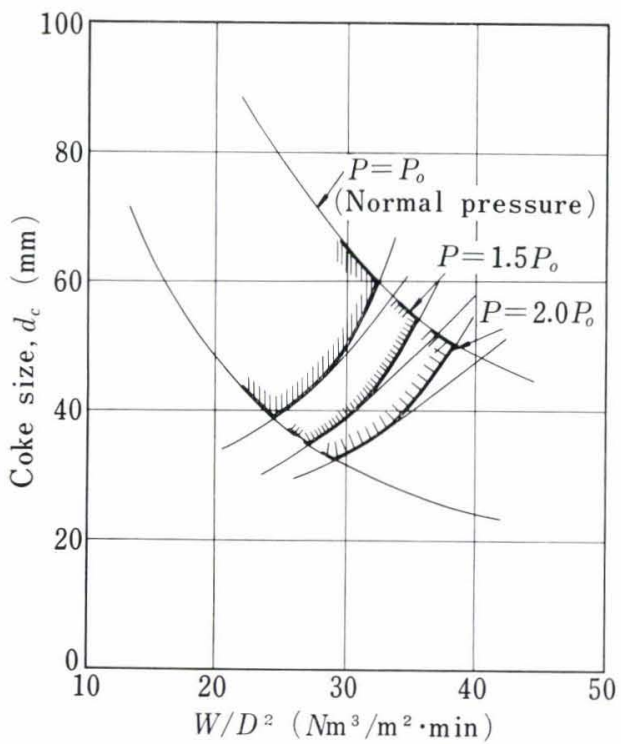

(a)

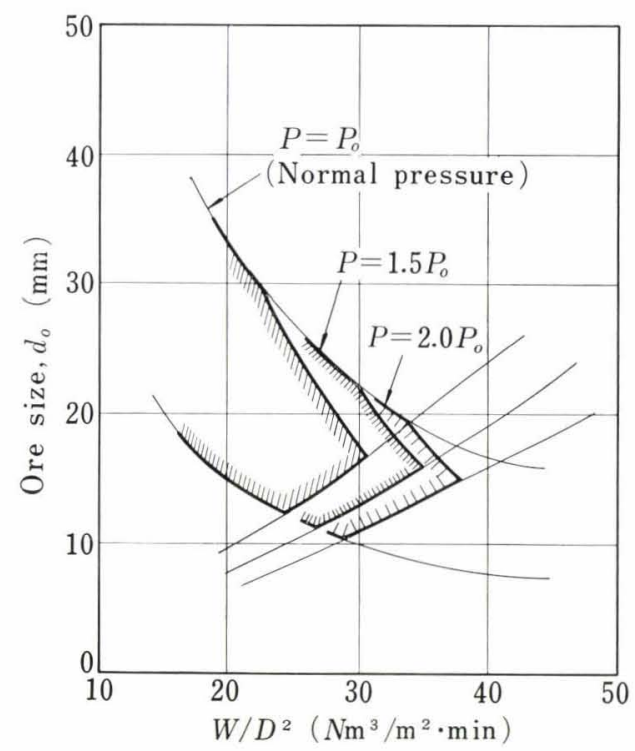

(b)

Fig. 7. Suitable range in high pressure operation (a) Coke size $d_{c}$ vs. $W / D^{2}$ (b) Ore size $d_{o}$ vs. $W / D^{2}$

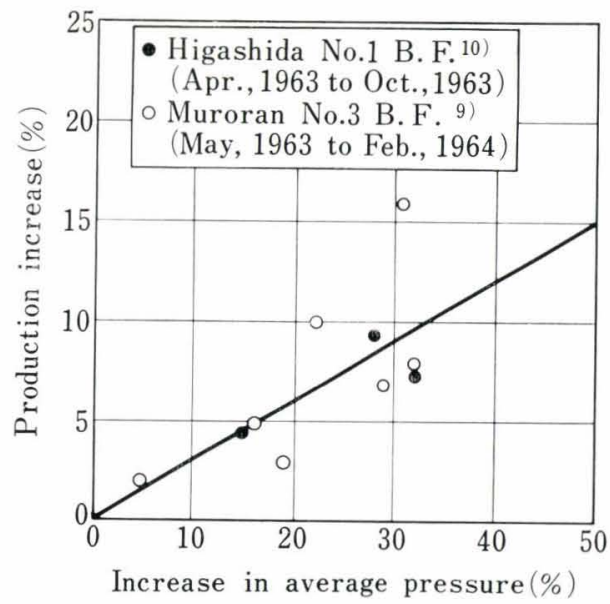

Fig. 8. Effect of gas pressure on productivity
Fig. 8 shows the effect of inner pressure on the production increase. These data were obtained from the practical high pressure operations of Higashida ${ }^{10}$ and Muroran ${ }^{9)}$ blast furnaces. In this figure, it is clearly shown that the practical production increase is approximately equal to the estimated value, and it seems to confirm the validity of the evaluation in this work.

It must however be noticed that more reliable experimental data are necessary for the high pressure reduction in order to make further discussion, since the reduction of iron ore is one of the most important limiting factors.

\section{Low-Shaft Furnace}

The method of analysis in the present work may also be applied to the low-shaft furnace, if the conditions in the furnace are not widely different from those in the blast furnace. The effect of furnace height on the suitable operation range is shown in Fig. 9 (a) and (b), in the cases of 20,25, and $30 \mathrm{~m}$ in the furnace

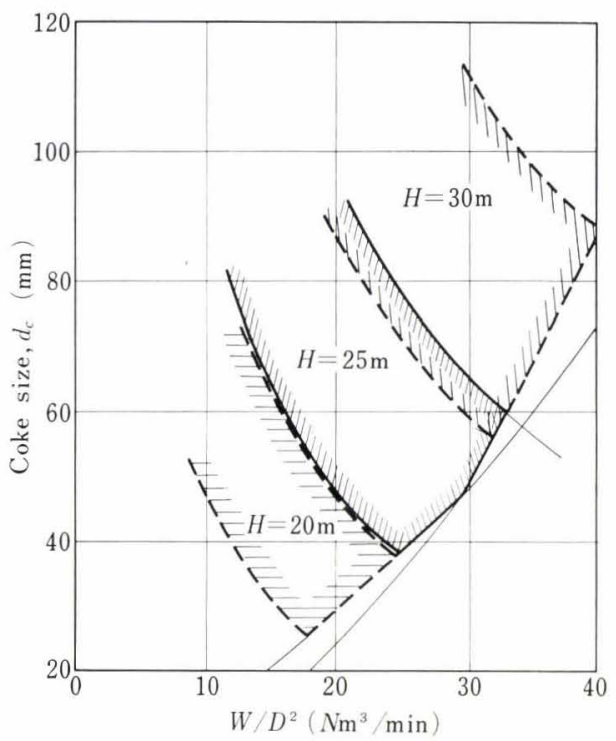

(a)

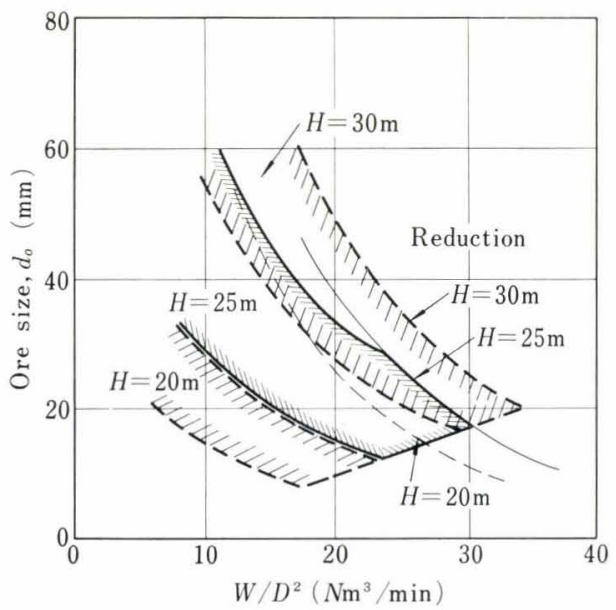

(b)

Fig. 9. Effect of furnace height $H$ on suitable operation range
(a) $d_{c}$ vs. $W / D^{2}$
(b) $d_{o}$ vs. $W / D^{2}$ 
height.

By the decrease in the furnace height, the lines of hanging and blowing-through do not move, but it causes a shortage of heat transfer and reduction and it makes the optimum size smaller. From Fig. 9 the following conclusions are obtained.

(1) Both the optimum grain size and the productivity limit decrease approximately in proportion to the furnace height.

(2) In the operation of low-shaft furnace, the blowing-through is the more important limiting factor as compared with the hanging, and also the heat transfer plays more important role than the reduction.

Of course, these considerations are also applicable to the comparison of the productivities of a large and small furnaces. The relation between $W / D^{2}$ and $H$ was examined from the practical operation data of the last four years. The result shown in Fig. 10 was thus obtained. In this figure, it is shown that $W / D^{2}$ is closely proportional to $H$ and this result seems to confirm the above-estimated.

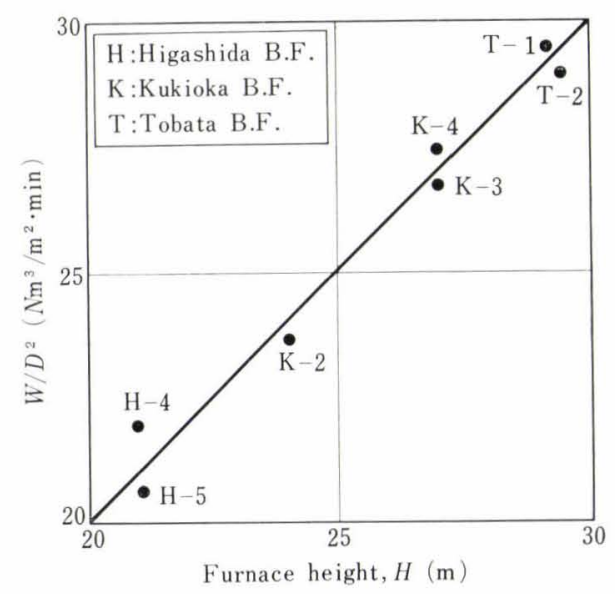

Fig. 10. Relation between $H$ and $W / D^{2}$ (Jan., 1961 to Jan., 1965)

Regardless of the furnace height, ore and coke having the grain size in a certain range are charged into the furnace in the most of the present blast furnace operations. However, the result described above shows that it is preferable to choose the size ranges by considering the furnace height.

\section{Summary}

By selecting the following four phenomena as the major restricting factors, the hanging due to flooding, the blowing-through, the heat transfer, and the reduction of iron ores, an analysis has been made on the blast furnace producibility limit. The results obtained are summarized as follows.

(1) The parameters which show a degree of those phenomena were found from the present investigation standing on the chemical engineering viewpoint. The critical values of these parameters were estimated from the data of recent practical operations, and the quantitative equations were derived to show the conditions necessary for the stable operation of the blast furnace. (Eqs. (25) to (28))

(2) It was shown that graphical presentations of these equations (Fig. 4 (a) and (b)) gave clear and synthetic information on the effect of each factor on the blast furnace productivity.

(3) By applying the results of the present analysis, some considerations were also given on the oxygen enriched, the high top pressure, and the low-shaft furnace operations. Some valuable informations for the selection of operation conditions were obtained as the result of this analysis. The production increase estimated for the above special operations showed a close agreement with the practical value.

\section{REFERENCES}

1) W. O. Philbrook: J. Metals, 6 (1954), 1396.

2) J. F. Elliott, R. A. Buchanan, and J. B. Wagstaff: Proc. Blast Furn., Coke Oven, and Raw Materials Conf., (1952), 246.

3) T. K. Sherwood, G. H. Shipley, and F. A. Holloway: Indust. Eng. Chem., 30 (1938), 765

4) S. Ergun: Indust. Eng. Chem., 45 (1953), 477.

5) P. Thierry, J. Szczeniowski, and J. Laborne: Iron \& Coal Trades Rev., 162 (1951), 1199.

6) K. Kodama, A. Shigemi, and T. Higashi : Tetsu-to-Hagané, 47 (1961), 271.

7) K. Kodama, A. Shigemi, and T. Higashi : Seitetsu Kenkyü, No. 237, (1961), 27.

8) T. Hasegawa, H. Nemoto, E. Sakamoto, and K. Kuroda: Tetsu-to-Hagané, 51 (1965), 628.

9) E. Iwamura, T. Kikuchi, T. Nagai, S. Yazaki, S. Hashizume, and T. Kadowaki: Tetsu-to-Hagané, 51 (1965), 1728.

10) Y. Shiroishi, K. Mitsui, M. Uchihira, H. Asai, and K. Mori : Tetsu-to-Hagané, 50 (1964), 353.

11) K. Segawa: Seitetsu Kenkyū, No. 235. (1961), 3320 ; No. 236, (1961), 3408. 